\title{
A MATLAB Program for Teaching Convective Heat Transfer
}

\author{
Craig W. Somerton, Mark Smith, Mike Lu \\ Department of Mechanical Engineering, Michigan State University
}

\section{Introduction}

Certainly, a key element to students' learning in engineering is the practice gained in working problems. The challenge for the instructor is in providing good problems that adequately challenge the student, but that do not go stale. A MATLAB program has been developed that will generate an infinite number of different convective heat transfer problems, prompt the student for an answer, check the answer, return the correct answer to the student, and track the student's performance. All interactions between the student and the program are through graphical user interfaces that have been developed using the guide function in MATLAB. The program begins by randomly generating a convective heat transfer problem. This is accomplished by using the Nusselt number classification scheme of Somerton et al [1], the following conditions are randomly decided:

\author{
Forced or Natural Convection \\ External or Internal Flow \\ Geometry \\ Flow Orientation (for forced convection) \\ or Surface Orientation (for natural convection)
}

Values of the physical parameters, such as temperatures and dimensions are also assigned using a randomizer. This approach involves more than just different numbers for the same problem statement. Different problems are generated depending on the randomly generated convective conditions.

With the problem presented to the student, it is expected that the student will work the problem out by hand and enter a numerical solution for the heat transfer rate. The student then clicks a button on the graphical user interface to indicate that they are ready for their solution to be checked. A convective solver is then run and a comparison is made between the solver's solution and the student's solution. If the comparison is within a certain tolerance the student's answer is deemed correct. The student's performance is tracked and they are provided with a count of the number of right answers to the total number of problems worked.

Though the problems generated by the program are still quite simple, they can still provide students with practice in honing their basic convective heat transfer problem solving skills. This is not a tool intended to help students build their modeling skills.

This paper continues with the details of the program development. This is followed by a demonstration of the program. Finally, conclusions and future directions for the program are presented. 


\section{Program Development}

Even though there are several excellent DOS programs in use for engineering education, it has become very clear that the current generation of engineering students are members of a point and click generation. Hence, any educational software that is truly going to be utilized by engineering students needs to have a graphical user interface (GUI). The software of the current paper was developed using MATLAB. MATLAB has a GUI developer that is accessed using the guide function. The developer is fairly straight forward to use and has proved adequate for the current software. MATLAB is also the principle computer software used in the undergraduate mechanical engineering program at MSU, so that the students are familiar with it. In designing the graphical user interface for the program, it was decided to use two dialog boxes. The first dialog box provides information about the program, and has a simple push button to access the second dialog box. This is shown in Figure 1. Upon clicking on the push button, the first dialog box is closed, and a second is open. As shown in Fig. 2, this dialog box consists of a title, below which is a list box that allows the student some choice in the type of convective heat transfer problem to be generated. Below the push button is a text box that displays the generated problem. At the bottom of the dialog box are three text boxes. The left hand box allows for the student to input their answer. Upon clicking the push button at the bottom, the correct answer is displayed in the right hand text box. In the center text box the student scoring appears. The various elements on these dialog boxes are created by dropping and dragging the elements from the MATLAB Guide Control Panel, which appears when the guide function is utilized. Each of these elements have a set of properties associated with them, such as color, font size, etc., that can be set using the Graphics Property Editor of MATLAB. The key component of the GUI development is setting the Callback property of an element. This property provides the action to be carried out when the element is clicked on by the user. The Callback for an element may include a few simple lines of MATLAB script code or it may call a MATLAB script program or function. For example, the push button on the first dialog box has the following MATLAB script code for its Callback:

Clc \{clears the MATLAB Command Window\}

fig2 \{runs the MATLAB script file fig2.m\}

NumProb $=0 ;\{$ initializes this variable to zero $\}$

NumCorrect $=0 ;\{$ initializes this variable to zero $\}$

close gcbf \{closes the current figure $\}$

The comments in the brackets indicate the action that is taken when the Callback is executed.

When more extensive action is required, such as generating the problem statement or generating a solution to the problem, it is sensible to use developer written MATLAB script programs or functions. To generate the convection problem four such programs were written for the following four convective situations:

Forced Convection, External Flow

Forced Convection, Internal Flow

Natural Convection, External Flow

Natural Convection, Internal Flow 
Figure 1 Opening Dialog Box.

(accessed by typing Convection at MATLAB Command Window prompt)

\title{
Welcome to the Convective Problem Generator and Solver
}

\author{
This is an Interactive Computer Software Program \\ Designed for Heat Transfer Students
}

Developed By Dr. Craig Somerton and Mark Smith

Copyright December 2000

Push Here To Continue 
Figure 2. Second Dialog Box.

\section{Select Which Type of Convection Problem You Want}

\begin{tabular}{l}
\hline Forced Convection - External Flow \\
Forced Convection - Internal Flow \\
Natural Convection \\
Any Convective Situation
\end{tabular}

Generate Problem

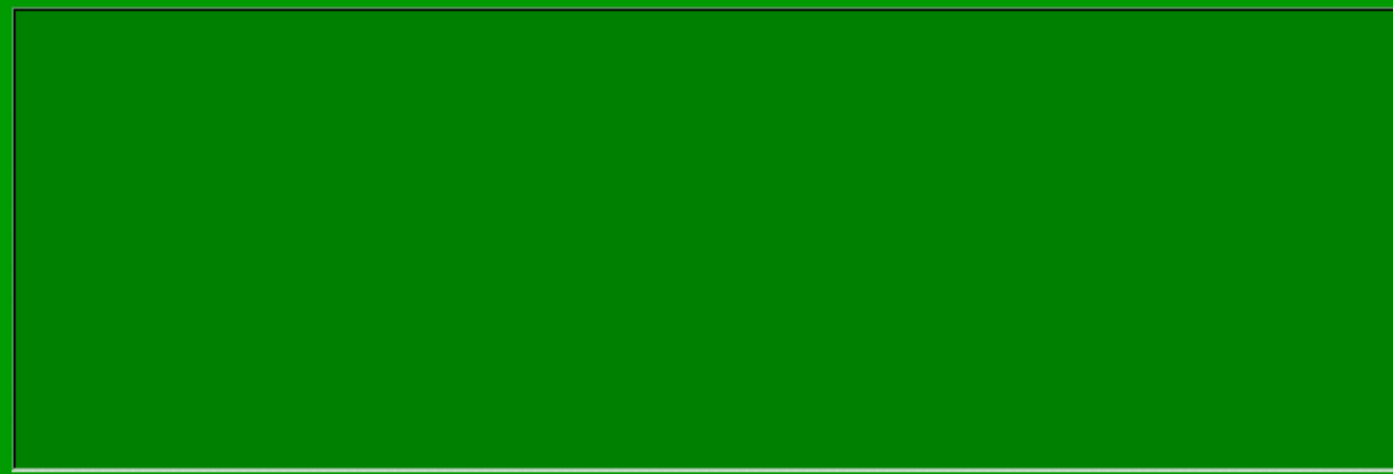

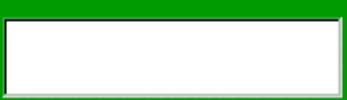

Enter Your Answer Here
$0 / 0$

Your Score

Check Your Answer 
If the user has chosen "Any Convective Situation" from the list box, then the decision as to which program to access is made by generating a random number of $1,2,3$, or 4 , and allowing this number to correspond to forced convection, external flow when it is equal to 1 , forced convection, internal flow when it is equal to 2 , and so forth. Then the appropriate MATLAB program is called. Each of these programs have a problem statement template. For example for the case of forced convection, external flow the problem template takes the form

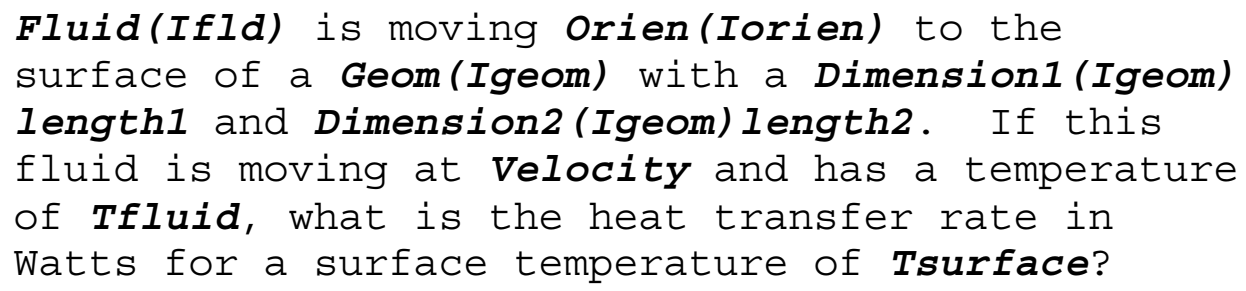

The bold/italicized words represent character string variables that are assigned within the program using the MATLAB sprintf function. Four different fluids are utilized in the program: air, water, superheated steam, and oil. There are two orientations possible: normal to the surface or parallel to the surface, though this may be suppressed if not appropriate for the geometry selected, for example a sphere. Several geometries are possible depending on the convective case. These are shown in Table 1. The numerical components of the problem, such as the surface temperature, Tsurface, are randomly generated within realistic bounds. That is, for air as the fluid the temperatures must lie within the range from $200 \mathrm{~K}$ to $2000 \mathrm{~K}$.

The convective solver that is executed when the bottom push button is clicked, has been written as a MATLAB function. While the problem is generated, the Somerton et al [1] convective classification system, shown in Table 2, was utilized. This information, along with the numerical values of the dimensions and temperatures, is passed to the solver function. This allows for the appropriate Nusselt number correlation to be identified and used to calculate the convective heat transfer coefficient and, eventually, the heat transfer rate. This value is compared to the value inputted by the user, and the user answer is deemed correct if it compares within $1 \%$ of the solver's value. Because of the great variability in Nusselt number correlations appropriate for a convective problem, the current software has been customized for a specific heat transfer book, that of Çengel [2].

\section{Program Demonstration}

To demonstrate the program we consider the problem generated in Fig. 3, which corresponds to the choice of Any Convective Situation from the list box. At this point it, the student would need to carry out the hand calculation for the problem. This is presented below using a standard problem solving framework. 
Table 1 Geometries Available for The Convective Cases.

\begin{tabular}{|l|l|}
\hline Convective Case & Possible Geometries \\
\hline \hline Forced Convection, External Flow & Flat Surface \\
& Sphere \\
& Cylinder \\
\hline Forced Convection, Internal Flow & Circular Duct \\
& Parallel Plates \\
& Rectangular Duct \\
\hline Natural Convection, External Flow & Flat Surface \\
& Sphere \\
& Cylinder \\
\hline Natural Convection, Internal Flow & Parallel Plates \\
& Concentric Cylinders \\
& Concentric Spheres \\
\hline
\end{tabular}


Table 2. Nusselt Number Classification System

\section{Flow Driving Force}

I. Forced Convection

II. Natural Convection

III. Mixed Convection

\section{Fluid Domain}
A. External Flow
B. Internal Flow

\section{Geometry}

1. Flat surface

2. Sphere

3. Cylinder

4. Tube Bank

5. Packed Bed

6. Annulus

7. Parallel Plates

8. Parallelepiped

9. Duct

10. Round Impinging Jet

11. Slot Impinging Jet

12. Hexagon

13. Ellipse

14. Triangle

15. Octagon

\section{Surface Orientation with respect to Gravity (for natural convection)}
a. Horizontal
b. Vertical
c. Inclined

Flow direction (for forced convection)
(i) Parallel to Axis
(ii) Normal to Axis
(iii) Oblique to Axis 
Figure 3 Demonstration Problem Statement

A. Figure No. 2

File Edit Iools Window Help

\section{Select Which Type of Convection Problem You Want}

\section{Forced Convection - External Flow \\ Forced Convection - Internal Flow \\ Natural Convection \\ Any Convective Situation}

Generate Problem

Air flows over the surface of a sphere with a diameter of $0.47 \mathrm{~m}$. If this fluid is flowing at $9.32 \mathrm{~m} / \mathrm{s}$ and has a temperature of $1145 \mathrm{~K}$, what is the heat transfer rate in Watts given a surface temperature of $565 \mathrm{~K}$ ?

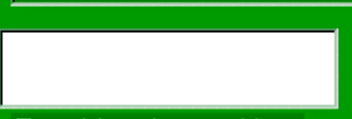

Enter Your Answer Here

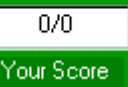

Check Your Answer
Correct Answer 


\section{Step 1}

We sketch our physical situation.

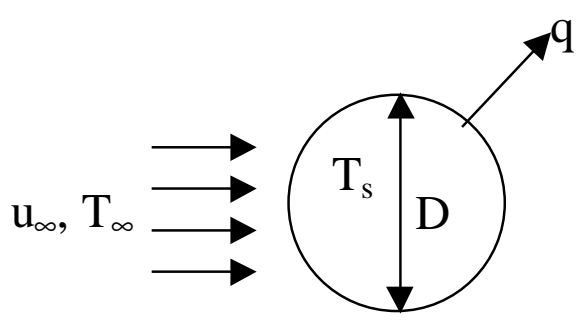
$\mathrm{D}=0.47 \mathrm{~m}$
$\mathrm{u}_{\infty}=9.32 \mathrm{~m} / \mathrm{s}$
$\mathrm{T}_{\infty}=1145 \mathrm{~K}$
$\mathrm{T}_{\mathrm{s}}=565 \mathrm{~K}$

Step 2

We wish to determine the heat transfer under the given convective conditions

\section{$\underline{\text { Step } 3}$}

Our overall energy balance will give

$$
\mathrm{q}=\mathrm{hA}\left(\mathrm{T}_{\infty}-\mathrm{T}_{\mathrm{s}}\right)
$$

where $\mathrm{h}$ will come from the appropriate $\mathrm{Nu}$ correlation calculation, and the surface area, $\mathrm{A}$, is given by

$$
\mathrm{A}=\pi \mathrm{D}^{2}=\pi(.47)^{2}=0.694 \mathrm{~m}^{2}
$$

$\underline{\text { Step } 4}$

Only one submodel, the sphere.

\section{$\underline{\text { Step } 5}$}

Model as Forced - External - Sphere - parallel and/or normal to surface

$$
\text { I-A-2-(i) or (ii) }
$$

The text by Çengel [2] suggest the use of the following Nusselt number correlation

$$
\mathrm{Nu}=2+\left[0.4 \mathrm{Re}^{1 / 2}+0.06 \operatorname{Re}^{2 / 3}\right] \operatorname{Pr}^{0.4}\left(\frac{\mu_{\infty}}{\mu_{\mathrm{s}}}\right)^{1 / 4}
$$

where the fluid properties are to be evaluated at the free stream temperature, except of $\mu_{\mathrm{s}}$, which is to be evaluated at the surface temperature. 
Using the property evaluator associated with the program we have at $1145 \mathrm{~K}$ for air

$$
\begin{aligned}
& \mathrm{k}=0.0756 \mathrm{~W} /\left(\mathrm{m}^{2} \cdot \mathrm{K}\right) \\
& \operatorname{Pr}=0.7126 \\
& \mu=4.6196 \times 10^{-5} \mathrm{~kg} /(\mathrm{m} \cdot \mathrm{s}) \\
& \nu=\frac{\mu}{\rho}=\frac{4.6196 \times 10^{-5}}{0.3057}=1.5113 \times 10^{-4} \mathrm{~m}^{2} / \mathrm{s}
\end{aligned}
$$

Then our Reynolds number is

$$
\operatorname{Re}=\frac{u_{\infty} D}{v}=\frac{(9.32)(0.47)}{1.5113 \times 10^{-4}}=29,984
$$

At a surface temperature of $565 \mathrm{~K}$ we have

$$
\mu_{\mathrm{s}}=2.955 \times 10^{-5} \mathrm{~kg} /(\mathrm{m} \cdot \mathrm{s})
$$

Our Nusselt number correlation then gives

$$
\mathrm{Nu}=2+\left[0.4(29984)^{1 / 2}+0.06(29984)^{2 / 3}\right](0.7126)^{0.4}\left(\frac{4.6196 \times 10^{-5}}{2.955 \times 10^{-5}}\right)^{1 / 4}=244
$$

and our heat transfer coefficient is

$$
\mathrm{h}=\frac{\mathrm{Nu} \mathrm{k}}{\mathrm{D}}=\frac{(244)(0.0756)}{0.47}=39.3 \mathrm{~W} /\left(\mathrm{m}^{2} \cdot \mathrm{K}\right)
$$

\section{$\underline{\text { Step } 6}$}

The heat transfer rate is then

$$
q=(39.3)(0.694)(1145-565)=15,805 \mathrm{~W}
$$

The numerical answer of 15,805 W can now be entered into the dialog box and the "Check Your Answer" push button is then clicked. As shown in Fig. 4, the correct answer is displayed, and the scoring box updated. We note that even though our calculated answer is not exactly the same as the program generated answer, $15,805 \mathrm{~W}$ to $15,821 \mathrm{~W}$, the user's answer is deemed correct by the program. Figure 5 shows the result of entering a wrong answer. 
Figure 4 Dialog Box with Correct Answer Input.

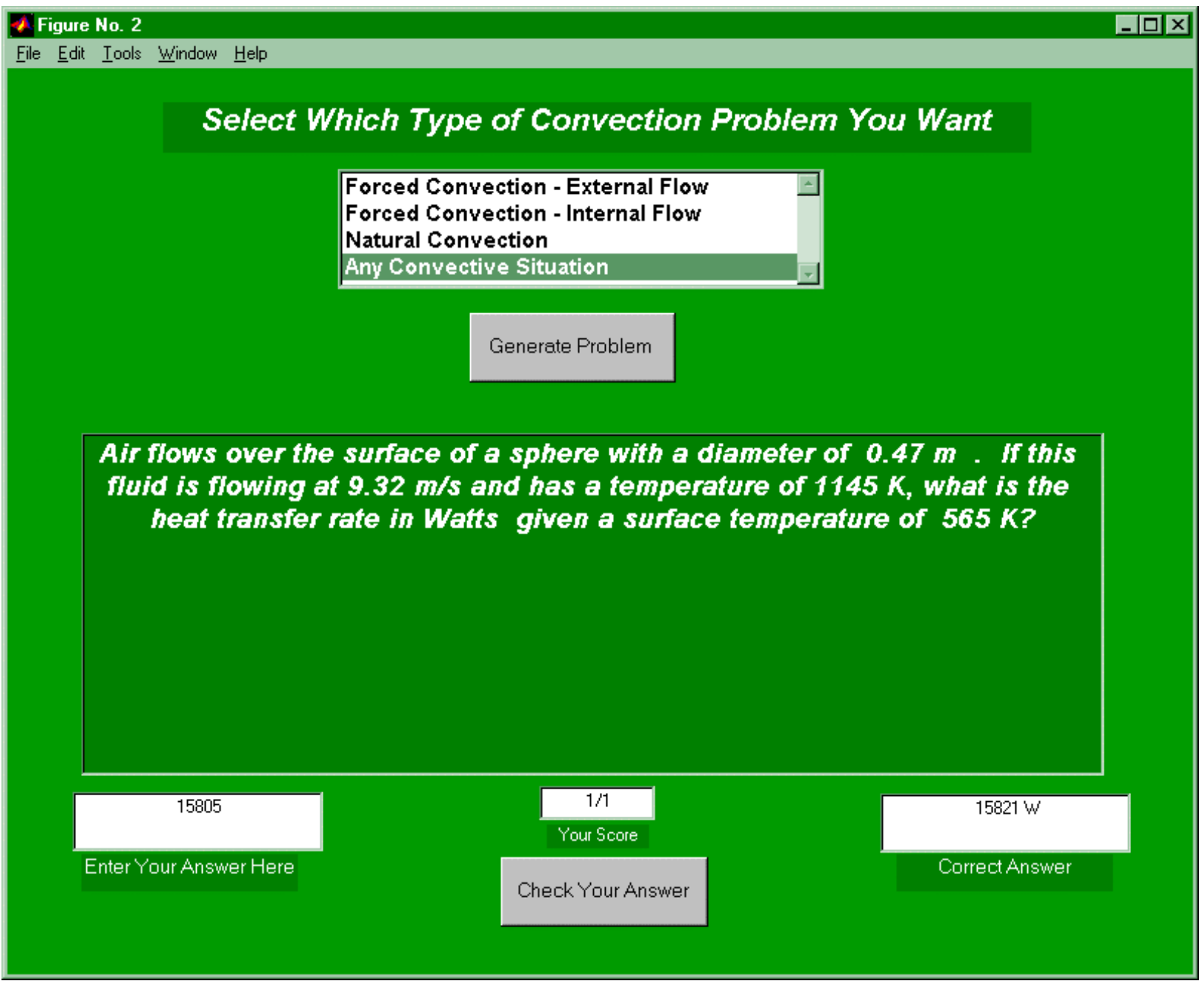


Figure 5 Dialog Box with Wrong Answer Entered

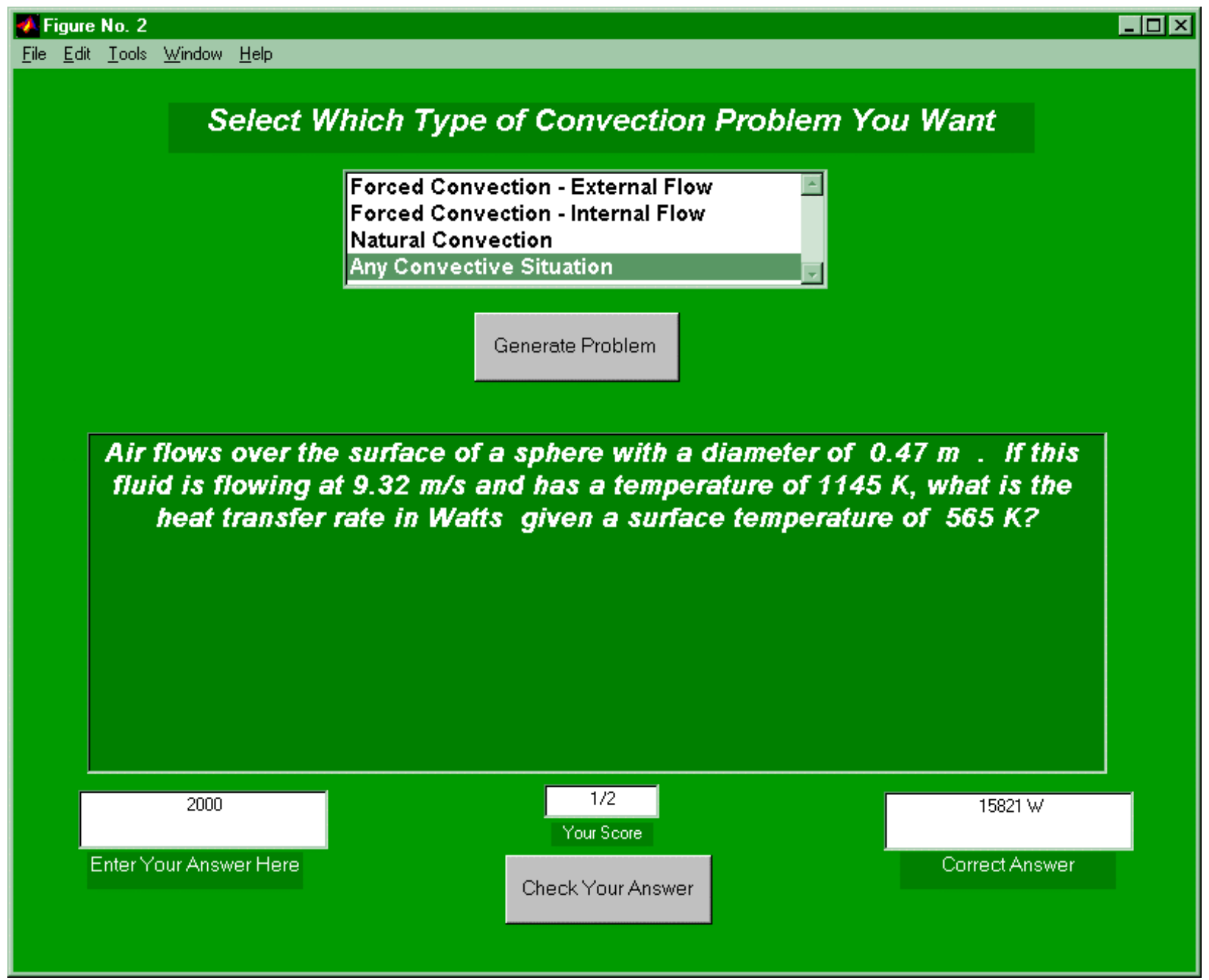

Proceedings of the 2001 American Society for Engineering Education Annual Conference \& Exposition

Copyright C 2001, American Society for Engineering Education 
To get a sense of the types of problems generated by the program, it was run ten times and the ten problem statements that were generated are presented in Table 3. It is interesting to note that of these ten problems five are forced convection and five are natural convection, which is consistent with the 50/50 distribution specified in the program. However, with respect to the fluid of the problem the distribution is

\author{
Air: 3 \\ Liquid Water: 5 \\ Superheated Steam: 2 \\ Oil: 1
}

This is nowhere near the even distribution set in the program. In fact the developers have noted that certain geometries also seem to appear more frequently than they should according to a random distribution. This may be due to the lack of a true random number generator.

\title{
Conclusions and Future Work
}

A computer program has been developed that should provide students with excellent opportunity to practice their basic convective heat transfer problem solving skills. The program runs in MATLAB and uses a graphical use interface to interact with the students. Currently the program is geared towards use with the heat transfer text by Çengel [2], but future work includes a second version of the software that is geared towards the text by Incropera and DeWitt [3]. The next version of the program will also include problems for which the surface temperature is the unknown. For the natural convection case these problems will require an iterative solution.

All of the software required to run the Convection Problem Generator and Solver are available for download at the Thermal Engineering Computer Aided Design (TECAD) homepage in the Department of Mechanical Engineering at Michigan State University. The URL address is

http://www.egr.msu.edu/ somerton/TECAD.

\section{Bibliography}

1. Somerton, C.W., Genik, L.J., Beavers, D., and Jammer, T., "A Nusselt Number Correlation Classification System", 1999 ASEE Annual Conference Proceedings, Charlotte, June 1999.

2. Çengel, Y.A., Heat Transfer: A Practical Approach, McGraw-Hill, Boston, 1998.

3. Incropera, F.P. and DeWitt, D.P. Introduction to Heat Transfer, $3^{\text {rd }}$ edition, John Wiley \& Sons, New York, 1996.

\section{CRAIG W. SOMERTON}

Craig W. Somerton is an Associate Professor of Mechanical Engineering at Michigan State University. He teaches in the area of thermal engineering including thermodynamics, heat transfer, and thermal design. Dr. Somerton has research interests in computer design of thermal systems, transport phenomena in porous media, and application of continuous quality improvement principles to engineering education. He received his B.S. in 1976, his M.S. in 1979, and his Ph.D. in 1982, all in engineering from UCLA.

\section{MARK SMITH}

Mark Smith is a December 2000 graduate of the BSME at Michigan State University. He was involved in the development of the graphical user interface for this work as an undergraduate research assistant. 
MIKE LU

Mike Lu is a May 2000 graduate of the BSME at Michigan State University. He was involved in the development of the convective solver for this work as an undergraduate research assistant.

Table 3 Ten Generated Problems from the Program

Air is flowing through a circular pipe with a diameter of $0.42 \mathrm{~m}$ and a length of $1.45 \mathrm{~m}$ at 5.80 $\mathrm{m} / \mathrm{s}$ and a temperature of $607 \mathrm{~K}$. What is the heat transfer rate for a surface temperature of 1244 $\mathrm{K}$ ?

Air is contained between two vertical parallel plates. The plates have a height of $1.35 \mathrm{~m}$ and a width of $2.47 \mathrm{~m}$ separated by a distance of $0.08 \mathrm{~m}$. The left surface is at $1222 \mathrm{~K}$, while the right surface is at $1630 \mathrm{~K}$. What is the heat transfer rate in Watts between the two surfaces?

Superheated steam flows over the surface of a sphere with a diameter of $0.87 \mathrm{~m}$. If this fluid is flowing at $3.05 \mathrm{~m} / \mathrm{s}$ and has a temperature of $980 \mathrm{~K}$, what is the heat transfer rate in Watts given a surface temperature of $993 \mathrm{~K}$ ?

Air is contained between two horizontal parallel plates. The plates have a length of $1.70 \mathrm{~m}$ and a width of $4.30 \mathrm{~m}$ separated by a distance of $0.13 \mathrm{~m}$. The top surface is at $942 \mathrm{~K}$, while the bottom surface is at $1540 \mathrm{~K}$. What is the heat transfer rate in Watts between the two surfaces?

Liquid water is flowing through a circular pipe with a diameter of $0.21 \mathrm{~m}$ and a length of 0.39 $\mathrm{m}$ at $6.80 \mathrm{~m} / \mathrm{s}$ and a temperature of $341 \mathrm{~K}$. What is the heat transfer rate for a surface temperature of $472 \mathrm{~K}$ ?

A sphere of diameter $0.04 \mathrm{~m}$ sits in still liquid water at a temperature of $375 \mathrm{~K}$. What is the heat transfer rate in Watts given a surface temperature of $277 \mathrm{~K}$ ?

A horizontal, flat surface of length $0.61 \mathrm{~m}$ and width $0.05 \mathrm{~m}$ sits in still superheated steam at a temperature of $311 \mathrm{~K}$. What is the heat transfer rate in Watts for the bottom side of the surface given a surface temperature of $433 \mathrm{~K}$ ?

Liquid water flows parallel to the surface of a cylinder with a diameter of $0.08 \mathrm{~m}$ and length of $1.36 \mathrm{~m}$. If this fluid is flowing at $6.93 \mathrm{~m} / \mathrm{s}$ and has a temperature of $389 \mathrm{~K}$, what is the heat transfer rate in Watts given a surface temperature of $323 \mathrm{~K}$ ?

A vertical, cylinder of diameter $0.55 \mathrm{~m}$ and length $0.36 \mathrm{~m}$ sits in still liquid water at a temperature of $420 \mathrm{~K}$. What is the heat transfer rate in Watts given a surface temperature of $507 \mathrm{~K}$ ?

Liquid water is flowing through a circular pipe with a diameter of $0.80 \mathrm{~m}$ and a length of 1.15 $\mathrm{m}$ at $2.30 \mathrm{~m} / \mathrm{s}$ and a temperature of $289 \mathrm{~K}$. What is the heat transfer rate for a surface temperature of $299 \mathrm{~K}$ ? 